\title{
Genetic Evaluation of Survival Traits in the Holstein Dairy Cows of Iran
}

\author{
Soheil Mirhabibi", Nasser Kashan*, Shahabodin Gharahveysi** \\ * Department of Animal Science, Science and Research Branch, Islamic Azad \\ University, Tehran, Iran. ${ }^{* *}$ Department of Animal Science, Qaemshahr Branch, Islamic \\ Azad University, Qaemshahr, Iran. Postal Address: Qaemshahr Branch, Islamic Azad \\ University- Tabarsi Road-Qaemshahr-Mazandaran-Iran, Postal code: 4849167119
}

\begin{abstract}
$\mathbf{T}$ HE longevity is an important functional trait for dairy cow breeders. The aim of this study is genetic evaluation of survival traits in the Holstein dairy cows of Iran. A data set of information from the Iranian Holstein dairy cows was used for this study. The culling date of 36340 animals from 65 herds recorded in 1993-2014 was used. Lifespan and Length of productive life (LPL) were analyzed for longevity. Functional productive life (FPL) was estimated. Production traits consisted of first lactation milk and fat yield. The (Co) variance, heritability and genetic correlation were estimated with multiple-trait REML using an animal model. The mean of lifespan and length of productive life were estimated to be $954( \pm 716)$ and $1710( \pm 721)$ days respectively. Heritability of LPL and FPL estimated as $0.032(0.012)$ and $0.028(0.012)$ respectively. The estimates of genetic and phenotypic correlations of milk yield with LPL and FPL were $-0.33,0.20,0.10$ and 0.25 , respectively. Due to the decline in length of productive life, with diagnosis of the involuntary culling in herds is possible to increase the longevity.
\end{abstract}

Keywords: Dairy cow, Functional productive life, Genetic correlation, Heritability, Longevity.

\section{Introduction}

In dairy cow the production traits are considered as primary and health, fertility and longevity as secondary or functional traits. During the last three decades with the improvement environment of factors (nutrition, hygiene and management) and genetic selection resulted the increase of milk yield. The 305 days of milk yield in Holstein cattle increased from 6500 (in 1970) to $9000 \mathrm{~kg}$ (in 2000) (9). Up to year of 2000 in most countries the functional traits were not considered in breeding programs. The decrease in fertility and longevity of the cows caused these traits to be considered in breeding program of different countries [1,2]. The longevity is an important functional trait for dairy cow breeders. Higher longevity in a herd reduce the replacement costs and improve the average herd yield through an increase in the proportion of cows in the higher producing age-groups and genetic selection for production.

The low heritability, lack of repeatability, sex limited and voluntary culling of the cows by farmers cause the genetic evaluation of the trait to be limited. In most cases the evaluation of the animals for this trait is through genetic correlation of production and type traits with longevity [3].

Longevity defined as lifespan, length of productive life (LPL) and functional productive life (FPL). Lifespan measures interval between birth and culling. Length of productive life measures days between age at first calving and culling. The Length of productive life corrected for milk yield is functional productive life. Longevity is affected by a number of non-genetic effects. The involuntary culling is defined as the removal of animal from the herd according to the health or fertility problems and the animals culled for low yield are in voluntary category. A well- planned herd is the one in which the manager can control high proportion of culling. Longevity is mostly determined by producers but breeding program can increase longevity in dairy cattle with the trait assigned in the selection indices. For this purpose, breeding value of the animals for this trait should be predicted and used for selection. Different studies suggest that by the increase of age of first 
calving the risk of culling in dairy cattle would be increased [4]. The heifers calve between the ages of 18-24 months will last longer than heifers calve at ages of more than 24 months [5].

The aim of this study is genetic evaluation of survival traits in the Holstein cattle of Iran.

\section{Material and Methods}

Data set structure

A data set of information from 75991 Iranian Holstein dairy cows was used for this study. This information was obtained from the animal breeding center of Iran. The data set consisted the culling date of 36340 cows (uncensored) and 39651 animals culling dates was not recorded (censored). The data recorded from two years 1993- 2014 from 65 herds. Records of the cows with age at first calving less than 600 and over 1200 days were removed from the data set.

\section{Statistical models}

The FPL was estimated using model 1 [6].

$\mathrm{FPL}_{\mathrm{ij}}=\mathrm{LPL}_{\mathrm{ij}}-\left[\mathrm{b}_{1}\left(\mathrm{y}_{\mathrm{ij}}-\overline{\mathrm{Y}}\right)+\mathrm{b}_{2}\left(\mathrm{y}_{\mathrm{ij}}-\overline{\mathrm{Y}}\right)\right]$

Where, $\mathrm{FPL}_{\mathrm{ij}}$ : functional productive life of cow $i$ in herd $j$; $L_{\text {PL }}$ : corresponding length of productive life of cow $\mathrm{i}$ in herd $\mathrm{j}$; $\mathrm{y}_{\mathrm{ij}}$ : percentage of 305 days milk yield of cow $\mathrm{i}$ relative to average 305 days milk yield in herd $\mathrm{j} ; \bar{y}$ : mean percentage of milk yield of all individuals relative to average milk yield over all herds; $b_{1}, b_{2}$ : linear and quadratic regression coefficients of functional productive life on the percentage of milk yield of the individual cow relative to herd average milk yield respectively.
Multivariate analysis for length of productive life and production traits was carried out using model 2:

$\mathrm{y}_{\mathrm{ijk}}=\mu+\mathrm{HYS}+\mathrm{b}_{1}\left(\mathrm{~A}_{\mathrm{k}}-\overline{\mathrm{A}}\right)+\left(\mathrm{A}_{\mathrm{k}}-\overline{\mathrm{A}}\right)^{2}+\mathrm{B}_{\mathrm{j}}+\mathrm{e}_{\mathrm{ijk}}$

Where, $\mathrm{y}_{\mathrm{ijk}}$ : observed value for longevity or production traits; $\mu$ : population mean; HYS: fixed effect of HYS, $B_{j}$ : random effect of animal; $\left(\mathrm{A}_{\mathrm{k}}-\overline{\mathrm{A}}\right)=$ deviation of the age at first calving associated with $\mathrm{y}_{\mathrm{ijk}}$ from the average age at first calving (days) fitted as linear and quadratic covariable; $b_{1}, b_{2}$ : linear and quadratics regression coefficients of $y_{i j k}$ on the age of first calving respectively; $\mathrm{e}_{\mathrm{ijk}}$ : residual effect.

Analysis

The GLM procedure was used to determine the variation of the trait. The $(\mathrm{Co})$ variance, $\mathrm{h}^{2}$ and genetic correlations were estimated with multipletrait REML with an Animal model using Wombat package [7]. To increase the accuracy of genetic parameters the information of the herds with at least 100 records of length of productive life and sires having at least 20 daughters were kept in the data set.

\section{$\underline{\text { Results and Discussion }}$}

Descriptive statistic of the traits under study is presented at the Table 1. The average 305 days milk yield in years 1991 to 2011 increased from 7000 to $11000 \mathrm{~kg}$. The mean of length of productive life in years 1992 and 2007 were 2000 and 1000 days, respectively. Some researchers have reported a negative relationship between longevity and milk production $[1,2,8]$. The mean of lifespan and length of productive life were $1710( \pm 721)$ and $954( \pm 716)$ respectively.

TABLE 1. Statistical parameter of production and reproduction traits.

\begin{tabular}{lcc}
\hline \multicolumn{1}{c}{ Traits } & Mean & Standard deviation \\
& & \\
\hline Calving intervals (days) & 396.80 & 67.60 \\
Open days (days) & 138.90 & 94.30 \\
Age at first calving (days) & 760.60 & 70.40 \\
Lactation period (days) & 344.40 & 84.20 \\
305 days milk yield (kg) & 10850.00 & 2285.00 \\
Fat yield (kg) & 299.20 & 91.00 \\
Protein yield (kg) & 287.40 & 86.90 \\
Fat percent & 2.70 & 0.78 \\
\hline
\end{tabular}


Similar declines were reported for length of productive life. The average length of productive life of Holstein dairy cattle in the Netherlands decreased from 4.5 years in 1979 to 3.5 years in 1986 [4]. The average length of productive life for Holstein cattle in US declined from 3.2 years in 1980 to 2.8 years in 1994 [8]. Decrease of longevity in dairy cattle happened in many countries in the last years. There was a negative genetic trend for longevity up to 2000 in various countries, but desirable genetic trends afterwards. The upward genetic trends is a reflection of increased attention on longevity in national selection indices [3,9].

Heritability estimates for LPL and FPL were low (Table 2) and in agreement with results from other investigations $[3,10,11]$. Because of culling a cow is a personal decision of the farmer, it can be reason for the low heritability of the trait. The literature show the heritability estimates for LPL are higher than FPL $[10,11]$. The correction of LPL for milk yield causes a proportion of genetic variance to be decreased and as a result the heritability of FPL to be less than of LPL. Genetic correlations of LPL with milk and fat yield were negative. These values were lower than estimates reported for Swiss brown [11], and for Holstein [10]. Genetic correlations of FPL with milk and fat yield were positive. The same correlations between FPL and these traits were found in literatures [11]. The phenotypic correlations between length of productive life and production traits were close to zero, which indicates that the adjustment removed phenotypic part of variance due to milk yield [12]. Low phenotypic correlations between production traits and FPL are reported [11].

TABLE 2. Heritability (diagonal), genetic (above diagonal) and phenotypic correlations (below diagonal) between production and productive life traits.

\begin{tabular}{lcccc}
\hline Trait & Milk yield & Fat yield & LPL & FPL \\
\hline Milk yield & 0.335 & ----- & -0.326 & 0.200 \\
Fat yield & ---- & 0.208 & -0.131 & 0.169 \\
LPL & 0.100 & 0.039 & 0.032 & ----- \\
FPL & 0.253 & 0.137 & ----- & 0.028 \\
\hline
\end{tabular}

\section{Conclusion}

Due to the decline in length of productive life also the low heritability and genetic correlations with production traits for longevity, with diagnosis of the involuntary culling in herds is possible to increase the longevity.

\section{Conflict of interest}

We certify that there is no conflict of interest with any financial organization regarding the material discussed in the manuscript. ......

Acknowledgements: The authors appreciate the efforts of all those participated in this study.

\section{References}

1. Berglund, B., Selection as a tool to increase dairy cow fertility. 20 March 2010, University of Padova, Italy. Avaiable at: http: // www. buiatria. it/ download/gb2010/ Selection_as_a_tool_to_ increase_dairy_cow_fertility.pdf (2010).
2. Egger-Danner, C., Cole, J.B., Pryce, J.E., Gengler, N., Heringstad, B., Bradley, A. and Stock, K.F., Invited review: overview of new traits and phenotyping strategies in dairy cattle with a focus on functional traits. Animal, 9 (2), 191-207(2014).

3. Caraviello, D.Z., Weigel, K.A. and Gianola, D., Comparison between a Weibull proportional hazard model and linear model for predicting the genetic merit of us jersey sires for daughter longevity. J. Dairy Sci., 87, 1469-1476 (2004).

4. Vollema, A.R. and Groen, A.F., A comparison of breeding value predictors for longevity using a linear model and survival analysis. J. Dairy Sci., 81, 3315- 3320 (1998).

5. Forbes, D., Gayton, S. and Mckeogh, B., Improving the longevity of cows in the UK dairy herd. Final Report for the Milk Development Council on the Results of the Longevity Project, which has been funded by the MDC, with further 
sponsorship from NMR and Kingshay Farming Trust, UK. Available at: https://dairy.ahdb.org. uk/non_umbraco/download.aspx ?media $=6779$ (1999).

6. Tesfaye, D., Genomics of fertility in cattle reproduction. Proceedings of the 3rd SABRE Conference- welfare and quality genomics, Foulum, Denmark, University of Aarhus (2008).

7. Meyer, K., WOMBAT A program for Mixed Model Analyses by Restricted Maximum Likelihood. USER NOTES. Version 1.0, Animal Genetics and Breeding Unit, University of New England, Armidale, NSW 2351, Australia. Avaiable at: didgeridoo.une.edu.au/km/download. php?file=WombatManual.pdf (2008).

8. Hare, E., Norman, H.D. and Wright, J.R., Survival rates and productive herd life of dairy cattle in the United States. J. Dairy Sci., 89, 3713-3720 (2006).
9. Van Doormaal, B., A closer look at longevity. Canadian Dairy Network. Available at: www.cdn. ca/document.php?id=162(2009).

10. Abdolmohammadi, A., Moradi-Shahrbabk, M. and Miraei Ashtiani, S.R., Estimation of genetic parameters for length of productive life and relation with production traits in Holstein cattle of Iran. Proceedings of the first congress on animal and aquatic sciences, Karaj, Iran, Tehran University (2002).

11. Vukasinovic, N., Moll, J. and Kunzi, N., Genetic relationships among longevity, milk production, and type traits in Swiss Brown cattle. Livest. Prod. Sci., 41, 11-18 (1995).

12. Dekkers, J.C.M., Theoretical basis for genetic parameters of herd life and effects on response to selection. J. Dairy Sci., 76, 1433-1443 (1993).

(Received 01/03/2018; accepted 24/06/2018)

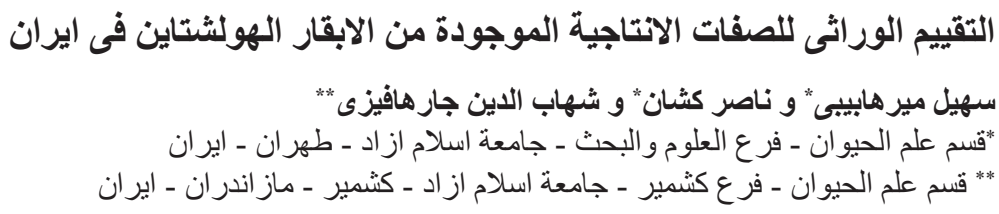

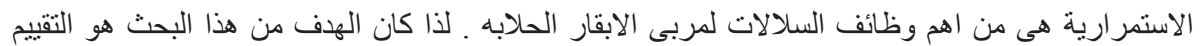

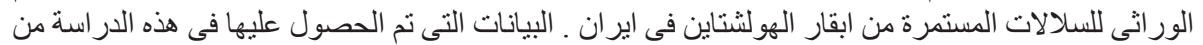

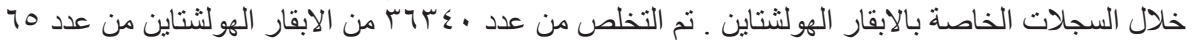

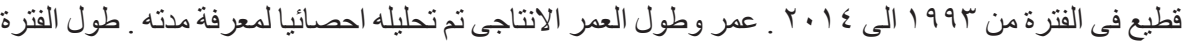

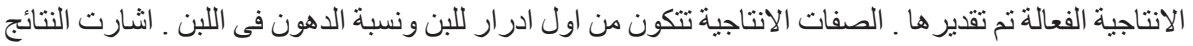

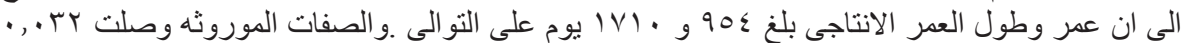

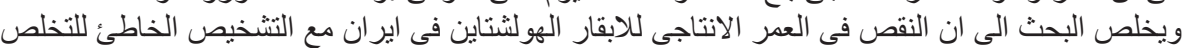

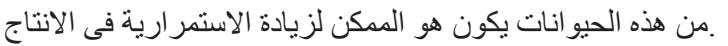
الكلمات الداله: الابقار الحلابة ، الفترة الانتاجية الفعالة ، العلاقة الور اثية. 